\title{
Ecological Niche Modeling Meets Phylogeography to Unravel Hidden Past History of Key Forest Genera in Plant Geography: Podocarpus and Nothofagus
}

\author{
Andrea Cecilia Premoli*, Maria Paula Quiroga, Paula Mathiasen \& Thomas Kitzberger
}

Laboratorio Ecotono, CRUB Universidad Nacional del Comahue - INIBIOMA CONICET, Bariloche, Argentina

\begin{abstract}
Phylogeographical methods and ecological niche modeling of cold-tolerant taxa, Podocarpus parlatorei a montane tropical conifer and Nothofagus pumilio inhabiting temperate areas of the southern Andes, were used as case studies to test if present populations are the result of local survival during cooling. Samples collected along their ranges were analyzed by nuclear isozymes and uniparentally inherited chloroplast DNA sequences. Modern and past last glacial maximum (LGM) ecological niche modeling (ENM) was developed using current climate data based on 19 bioclimatic variables and topography. Populations of the subtropical of $P$. parlatorei shared most haplotypes, southern populations were genetically distinct, and ENM yielded range expansion during the LGM. Latitudinally extreme populations of the temperate $N$. pumilio shared isozyme variants which was consistent with ENM showing suitable northern and southern areas. In contrast cpDNA yielded an ancient phylogeographic structure. Cold-hardy trees locally persisted along their ranges through ice periods without major range shifts in tropical and temperate regions.
\end{abstract}

Key words: Chloroplast DNA, Cold-tolerant Trees, Distribution Modeling, Montane Subtropical, Temperate Andes.

\section{Introduction}

Phylogeographical analyses based on conserved molecular markers are being widely used for biogeographic reconstructions and to understand past history. Molecular markers including uniparentaly chloroplast DNA (cpDNA) polymorphisms in plants result from ordered mutation sequences that can be reconstructed by parsimonious algorithms. Such molecular information has provided valuable information to decipher areas of long-term persistence of lineages and expansion routes from them.

Quaternary climate changes have been considered one of the main drivers of gene genealogies (Hewitt 2000). For tree taxa that were severely affected by climate oscillations of the Quaternary, phylogeographic patterns aided in the identification of refugial areas during the ice ages towards warmer latitudes and postglacial recolonization routes after glacial retreat. Yet, different predictions can be drawn for species with distinct ecological characteristics. If species persisted in suitable habitats within a single extended area (single refugium hypothesis sensu Premoli et al. 2000), more recently colonized populations will hold relatively reduced genetic diversity due to founder effects that occurred during

\footnotetext{
${ }^{*}$ Send correspondence to: Andrea Cecilia Premoli Laboratorio Ecotono, CRUB Universidad Nacional del Comahue - INIBIOMA CONICET,

Quintral 1250, 8400 Bariloche, Argentina

E-mail: andrea.premoli@gmail.com
}

the long distance migration process yet they will also be genetically similar to source populations due to shared ancestry. While such responses to cold periods may fit well for warm-loving species, distinct phylogeographic patterns may be predicted for cold-tolerant lineages. If species were able to survive in multiple locales along their current range (multiple refugia hypothesis sensu Premoli et al. 2000) populations will be genetically divergent due to the combined effects of drift and isolation (Petit et al. 2003). Although genetic predictions maybe affected by individualistic colonizing abilities of tree taxa (Petit et al. 2003) fossil records and climatic settings drawn from them may greatly contribute to unravel species' responses. Extensive pollen records from temperate areas of South America show rapid vegetation change suggesting the expansion from local and widely scattered patches of forest that survived the full glacial. Local survival of cold-hardy taxa was also supported by minor amplitude of climate change during many glacial-interglacial cycles in southern latitudes which in turn have no equivalent to the vast continental-scale migration events of the northern hemisphere (Markgraf et al. 1995). Similarly, mountain regions of the tropics provided through the ice ages a stable humid habitat in which older lineages may persist by altitudinal shifts (Hewitt 2000). Hence, population genetic studies on trees prompted the idea of in situ survival through cold periods in multiple ice-free areas (Premoli et al. 2000) from Patagonia later confirmed 
in several other plant taxa (reviewed by Sersic et al. 2011) and in tropical mountains of South America (Quiroga \& Premoli 2007).

While fossils have been traditionally used to test biogeographic scenarios, the usefulness of the pollen record has some limitations. This is the case of widespread cold-tolerant lineages as Nothofagus and Podocarpus endemic to southern biotas. Nothofagus was historically considered a key genus in plant geography (van Steenis 1971). This was due to its disjunct distribution in land masses formerly connected as part of Gondwana, abundant and clearly distinguishable fossil record including macrofossils, and restricted seed dispersal. As a result, its distribution was used as a classic example of the effects of vicariance driving patterns of divergence (Hill 2001) and more recently long distance dispersal (Knapp et al. 2005). Alike Nothofagus, Podocarpus has a rich fossil record and a widespread distribution in Southern Hemisphere continents reaching tropical latitudes as a result of dispersal and vicariance from austral sources. Therefore, they can be considered emblematic genera to test biogeographic hypotheses. For both genera, ecologically distinct species are undistinguishable from pollen records. In particular, fossil evidence suggests that since the subgenera appeared, evolutionary change within Nothofagus has been slow (Hill 2001). Similar morphological stasis was recorded in Podocarpus (Kershaw \& McGlone 1995) and as a result, identifications are limited to the generic level (Hooghiemstra et al. 2006). Thus, species-specific biogeographical reconstructions as well as inferences of prevailing environmental conditions including climates based on pollen may be biased. This is in addition to interpretations of low pollen abundances, which are often explained as recent arrival from far away sources (e.g. Villagrán 1991). Nonetheless, they may also be the result of local survival as small populations (e.g. Premoli et al. 2000). Such contrasting scenarios, i.e. colonization through dispersal versus in situ persistence, may have different genetic outcomes, which should be considered when predicting phylogeographic patterns. This suggests the need for other proxy, such as ecological niche modeling (ENM) in combination with fossil data and phylogeographic evidence to reconstruct historical scenarios.

Ecological niche modeling provides a rigorous assessment of spatially explicit scenarios during different time periods and offers the ability to identify processes operating at the population level. The use of ENM can be projected onto paleoclimate reconstructions to identify suitable areas and past potential distributions (Waltari et al. 2007) under the assumptions of niche conservatism (MartínezMeyer \& Peterson 2006) and equilibrium of species with environmental conditions. Thus ENM approaches provide a priori hypotheses on the location of suitable areas during cooling and thus to identify glacial refugia. While some studies show concordant ENM and molecular patterns (Waltari et al. 2007; Knowles et al. 2007) other examples exist in the literature that to some extent, yield conflicting phylogeographical results with model predictions (eg. Carnaval \& Moritz 2008).

We hereby combine phylogeographic methods by means of sequences of cpDNA, population genetic data using isozymes, ecological niche modeling, and temperature simulations to analyze whether cold-hardy trees were able to locally respond to climate oscillations along their natural range in tropical and temperate mountain areas without major range shifts. We chose as study cases published data on Podocarpus parlatorei the unique montane conifer in the subtropical Yungas forests and Nothofagus pumilio that inhabits temperate high-elevation and high-latitude areas of Patagonia. These two species are widespread along their latitudinal distribution and they define the forest type wherever they occur. In addition to problematic taxonomic identification of fossils, the integration of molecular data with ENM is relevant because of the lack of fossil records within P. parlatorei current range.

\section{Material and Methods}

Samples were collected from the entire range of the two widespread species. Given that N. pumilio occupies altitudinal gradients only low elevation populations were sampled to control for such altitudinal variation. Sampled populations of $P$. paraltorei consisted of 3 sites from Bolivia, and 18 from Argentina, while the populations of N. pumilio included 32 locations from Chile and 53 from Argentina (see Tables S1 and S3 on the Additional Supporting Information available at www.abeco.org.br). Fresh leaf material was collected from all individuals for cpDNA and isozyme analyses. Isozyme markers are nuclear and thus biparentally inherited and those of the chloroplast are paternally and maternally inherited in P. parlatorei and N. pumilio, respectively. Between two and 10 individuals were randomly sampled for chloroplast DNA (cpDNA) analyses from each population. A total of 208 individuals of $P$. parlatorei were sequenced for the cpDNA noncoding region of the intergenic spacer trnL-trnL (LF). Other 16 regions including those of the chloroplast, the mitochondria, and nuclear were screened in P. parlatorei that yielded no polymorphism (Table S2 on the Additional Supporting Information available). A total of 194 individuals of $N$. pumilio were sequenced for three cpDNA noncoding regions, the psbB-psbH (BH), trnL-trnF (LF) and trnH-psbA (HA) intergenic spacers. A subset of 18 populations (one from Bolivia, and 17 from Argentina), with a total of 477 individuals of $P$. parlatore $i$ were analyzed by 16 isozyme loci. In the case of $N$. pumilio 40 populations ( 6 from Chile, and 34 from Argentina), with a total of 1183 individuals were also screened for isozyme variation based on 8 putative loci. Laboratory protocols of amplification and sequencing of DNA regions as well as isozyme analyses are provided as Additional Supporting Information. Available DNA sequences were aligned with Mega 4 (Tamura et al. 2007). The relationships among different haplotypes were performed by minimum spanning network of haplotypes with the program Network 4.5 (fluxus-engineering.com) 
under the assumption of Median Joining (Bandelt et al. 1999). Cluster analyses (UPGMA - Unweighted Pair Group Method with Arithmetic Mean) based on modified Rogers genetic distances were used to evaluate the genetic relationships using isozymes between all population pairs.

Ecological niche model (ENM) was implemented using MAXENT algorithm (see Phillips et al. 2006) for both species under modern conditions and projected into glacial maximum (LGM) conditions, based on a set of bioclimatic and topography variables selected using Jackknife for current climate data (see Additional Supporting Information at www.abeco.org.br for details). A total of 78 localities for $P$. parlatorei were included in the ENM. Multiple information sources for presence localities of $P$. parlatore $i$ were used in the niche models. These were obtained from the sampled populations for genetic studies, the Subtropical Network of 1-ha Permanent Plots (RedSPP) belonging to Fundación ProYungas, 0.1-ha circular plots from rapid presence surveys, public databases (Global Biodiversity Information facility, http://www.gbif.org/; Tropics, http://www.tropicos.org/Home. aspx), and the National Herbarium of Bolivia (Quiroga et al. 2012). Present-day occurrence data of $N$. pumilio was compiled from a variety of sources: 1:500,000 Valdivian Ecoregion Map, Argentinean 1st Native Forest Inventory, Chilean Native Forest Cadastre 1:500,000 (Premoli et al. 2010). Last glacial maximum climate was derived from the Community Climate System Model (NCAR-CCSM). Raster occurrence data was vectorized to points to obtain geographic coordinates of localities, removing duplicate records coming from overlapping data sources. To reduce spatial autocorrelation we removed from the training set those localities within 1' latitude from each other.

To develop ENM we used current (pre-industrial) climate data at $30^{\circ}(-1 \mathrm{~km})$ spatial resolution from the WorldClim database (Hijmans et al. 2005). This database provides 19 bioclimatic variables that represent summaries of means and variation in temperature and precipitation, and likely summarize dimensions of climate particularly relevant in determining species distributions. In addition, we used elevation, slope, and aspect derived from the Digital Elevation Model Shuttle Radar Topography Mission (SRTM-90) dataset. A subset of spatially explicit environmental and topographic datasets for the southern South American region $\left(60-80^{\circ} \mathrm{W}, 30-56^{\circ} \mathrm{S}\right)$ was used for the development of ENMs (see Additional Supporting Information).

To create LGM climate layers for the ENMs, we used LGM bioclimatic data at 2.5 ' spatial resolution that were drawn from the 21 kyr BP simulations using the Community Climate System Model (NCAR-CCSM; Collins et al. 2004). We downscaled bioclimatic surfaces to 30 " spatial resolution following Waltari et al. (2007). First, we calculated the differences between LGM and recent (preindustrial) conditions at the native coarse resolutions. These differences were then interpolated to 30 " spatial resolution using the spline function in ArcMap (ESRI, Redlands, CA) with the tension option. Finally, the interpolated difference maps were added to the WorldClim current 30 " climate data to obtain the downscaled 30" bioclimatic dataset corresponding to LGM (21 kyr BP).

Using the Community Climate System Model (NCARCCSM) we simulated the reduction during LGM in mean annual temperature along the Atlantic coast of southern South America. This model has been recently validated over the Atlantic Ocean comparing simulated with multi-proxy reconstructions of mean annual and seasonal sea surface temperatures (SST; Clauzet et al. 2008), showing better agreement in the western and central part of the South Atlantic.

\section{Results}

Phylogeographic structure of the tropical montane P. parlatorei consisted of common haplotypes that were present throughout the entire latitudinal distribution of the species. In addition other more geographically restricted haplotypes were found along the range with highest haplotype diversity towards the center of the distribution. Nonetheless, unique haplotypes were also present at distinct locations (Figure 1). Ecological niche modeling yielded a widespread and more extended total range during the last glacial maximum compared to a more fragmented current distribution. In particular, during cold periods, P. parlatorei expanded its range towards lower elevations, the east and the south while becoming increasingly restricted during current interglacial (Figure 2a, b). Compared to modern data, NCAR-CCSM simulates a reduction in mean annual temperature between c. -4 and $-5^{\circ} \mathrm{C}$ during LGM (Figure 2c). Cluster analysis yielded a cophenetic correlation, i.e. a measure of how faithfully the tree represents the dissimilarities among observations, of 0.969. Most central populations clustered together by means of isozyme nuclear markers whereas southern-most and one eastern population where clearly distinct (Figure 2d).

Phylogeographic analyses by sequences of three non-coding cpDNA regions on temperate $N$. pumilio yielded two clearly distinct and latitudinally structured groups of populations located north and south $43^{\circ} \mathrm{S}$ latitude (Figure 3). Ecological niche modeling showed high suitability during cold periods towards the current northern range while other areas existed further south and towards the east including those in austral-most latitudes in the island of Tierra del Fuego (Figure $4 \mathrm{a}, \mathrm{b}$ ). Simulation by NCAR-CCSM yielded a reduction of mean annual temperature during LGM above -6 ${ }^{\circ} \mathrm{C}$ at the latitudinal extremes getting colder at mid-latitudes and towards the west (Figure 4c). Multivariate analysis of $N$. pumilio by isozymes (cophenetic correlation $=0.986$ ) showed that latitudinally distant populations were grouped together while mid-latitude populations differed genetically (Figure 4d).

\section{Discussion}

Cold-hardy trees inhabiting mountain areas of tropical and temperate regions were able to locally persist or 


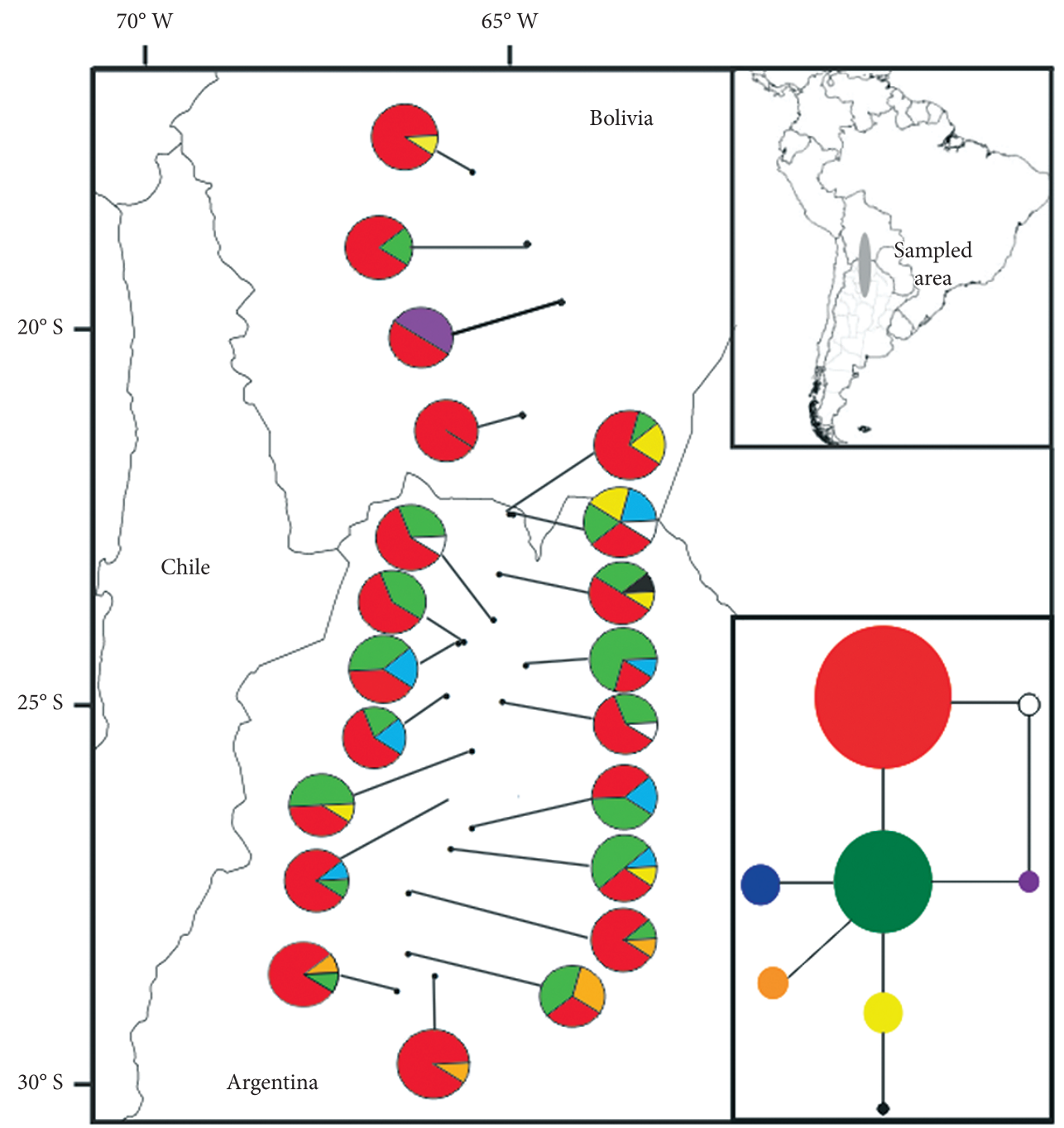

Figure 1. Distribution of 8 cpDNA haplotypes based on sequences trnL-trnF intergenic spacer for 21 sites of the montane subtropical Podocarpus parlatorei. The inset graphic represents a Median-Joining network showing the relationships among haplotypes. Circle size is proportional to the haplotype frequency.

even expand their range during cooling. In the tropics, common cpDNA haplotypes as well as genetically similar populations by nuclear markers call for population expansion most probably from a core area towards the center of the distribution. This is reinforced by ecological niche modeling showing range expansion during ice ages and moderate temperature decrease within the study area during the LGM. Thus $P$. parlatorei was able to colonize southern latitudes and lowland terrains towards the east during cooling which was probably facilitated by the extirpation of warm-loving taxa due to their susceptibility to low temperatures. Given that cpDNA is paternally inherited in Podocarpus, the presence of unique cpDNA haplotypes reflects a contemporaneous signal of isolation similar to the significant geographical structure detected by nuclear markers (Quiroga \& Premoli 2007). Most cold-tolerant taxa of the modern forests are still well adapted even into an interglacial such as nowadays conditions given that cooler times have comprised most of the last million years. The significant environmental stress to these forests comes with interglacial warming which devastates populations that tend to migrate toward higher elevations (Colinvaux \& De Oliveira 2001). As a consequence, cold-hardy biota is adapted to "normal" glacial conditions, and interglacial warm peaks can be viewed as "disturbances" (Colinvaux \& De Oliveira 2001; Rull 2009). Therefore, sensitive taxa to warming had to endure upward migration to montane refugia (Bush 2002) which is reflected in the phylogeographic and genetic structure of $P$. parlatorei.

In temperate areas, population genetic evidence by means of isozymes clearly suggests that $N$. pumilio consists of an ancient gene pool that was latitudinally fragmented (Mathiasen \& Premoli 2010; Premoli et al. 2010). Ecological niche modeling and temperature simulations agree with 

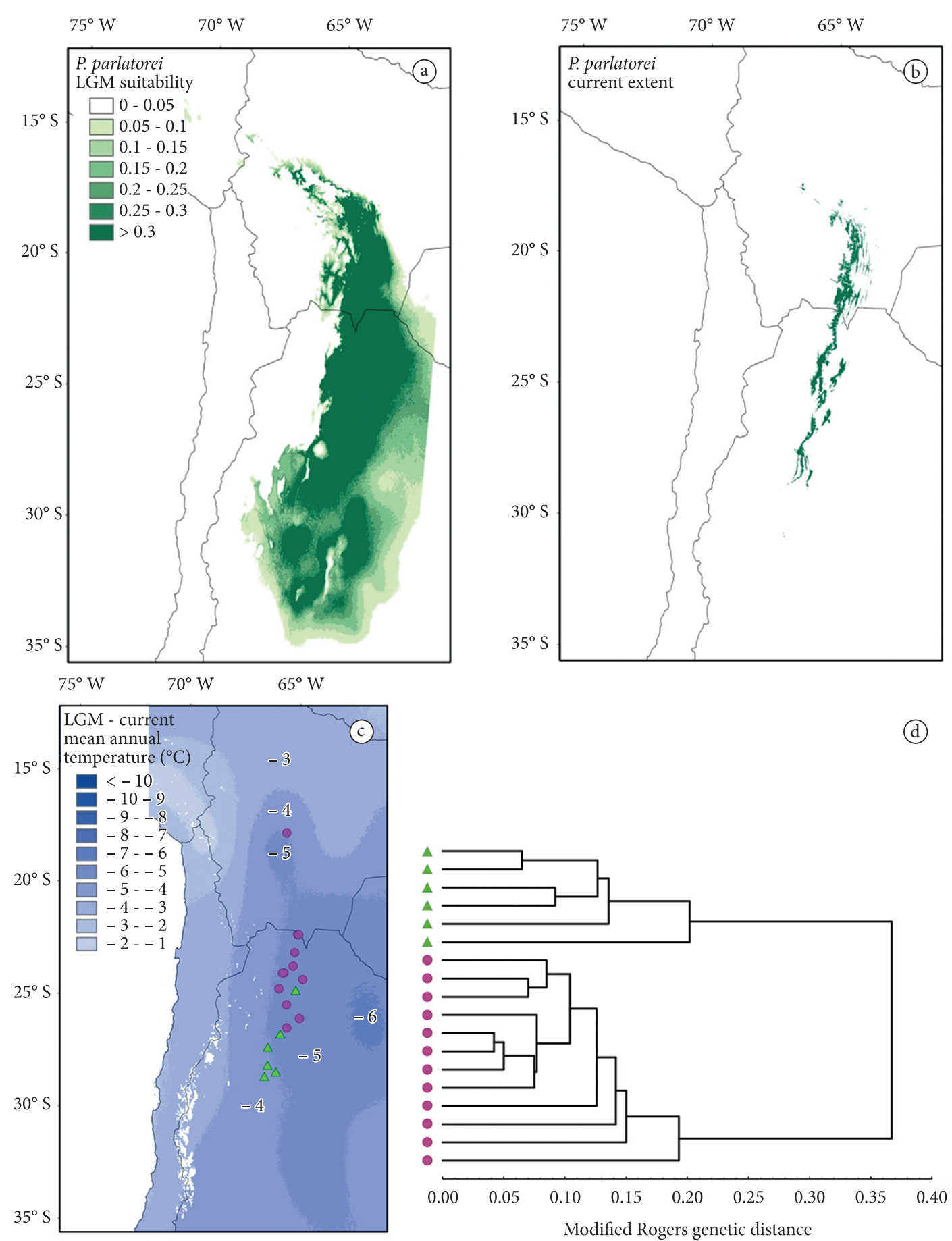

Figure 2. a) Modeled distribution of Podocarpus parlatorei during Last Glacial Maximum in southern South America using the Maxent model based on the NCAR-CCSM GCM; and 16 kyr icesheet boundary, light blue; b) Present-day occurrence data of Podocarpus parlatorei forests; c) LGM-modern difference in mean annual temperature simulated by the NCAR-CCSM GCM. Superimposed are site locations of populations sampled for genetic analyses (northerly population magenta circles, southerly populations green triangles), and d) Multivariate cluster analysis based on isozyme data of Podocarpus parlatorei populations along its entire range; coding corresponds to that described in panel c.

this scenario which is also concordant with reconstruction of glacier fluctuations in Patagonia showing that the central sector of the icesheet between latitudes $43^{\circ}$ and $53^{\circ} \mathrm{S}$ was the most glaciated area under the LGM climatic conditions
(Hulton et al. 2002). Although isozyme variants mirror contemporaneous effects of genetic drift and isolation, a more conserved signal is obtained by cpDNA markers. Phylogeographic patterns by cpDNA in all species within 


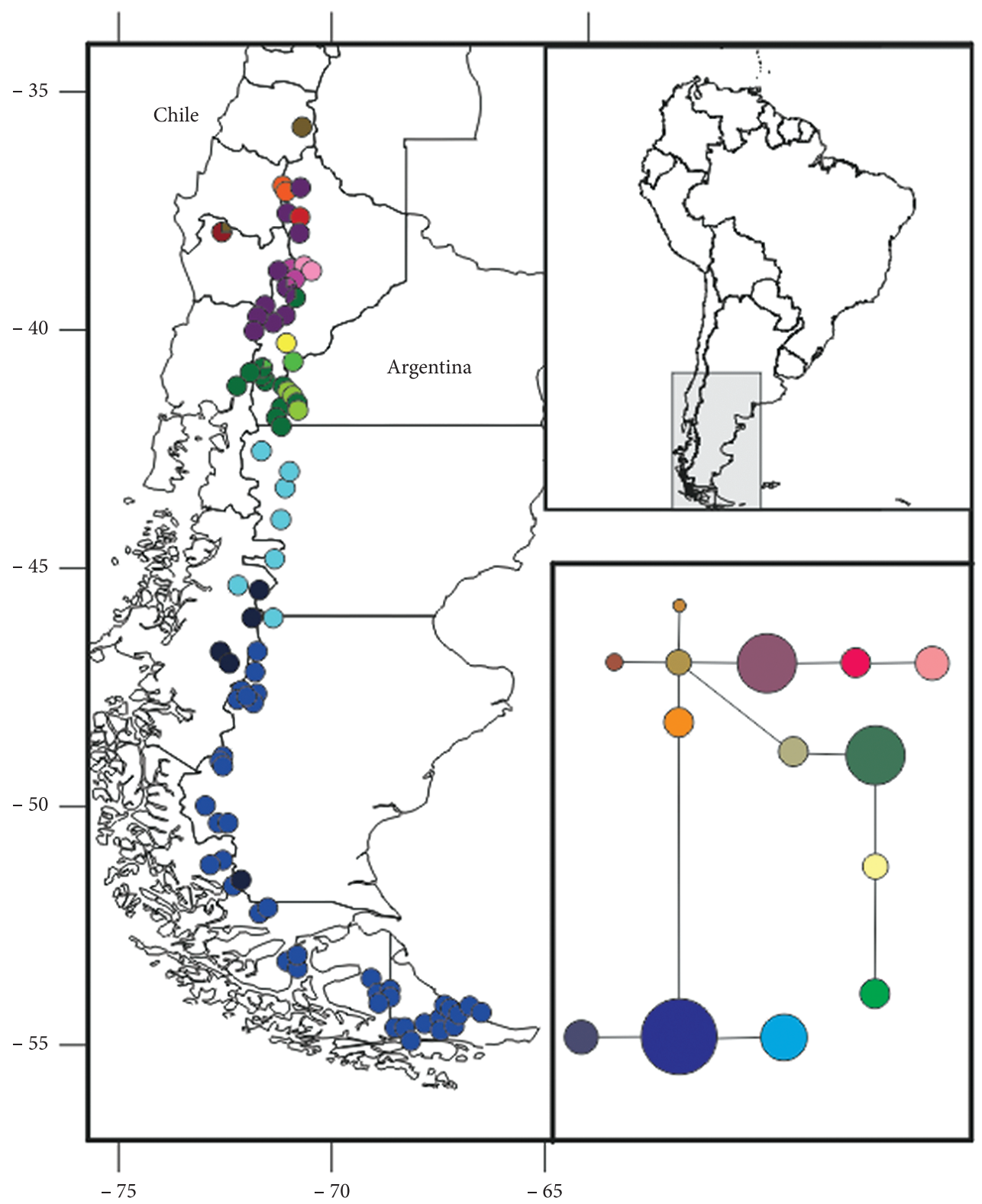

Figure 3. Distribution of 14 cpDNA haplotypes based on the combined sequences of BH, LF and HA intergenic spacers for 85 sites of the temperate Nothofagus pumilio. The inset graphic represents a Median-Joining network showing the relationships among haplotypes. Circle size is proportional to the haplotype frequency.

subgenus Nothofagus including N. pumilio show reciprocal monophyly of two latitudinally divergent lineages (Acosta \& Premoli 2010; Premoli et al. 2012). Under glacial scenarios of long distance dispersal austral populations should have been derived from those located towards warmer northern areas (Villagrán \& Hinojosa 2005). The lack of common as well as intermediate haplotypes along more than $2000 \mathrm{~km}$ provide unequivocal evidence that north and south cpDNA clades of $N$. pumilio have been historically isolated and that neither of them has derived from the other (Mathiasen \& Premoli 2010). Hypotheses of either extinction of common haplotypes along the range or the loss of northern haplotypes in the south and vice versa seem unlikely given that our study comprises the entire latitudinal and longitudinal distribution of $N$. pumilio. In addition, geographically concordant phylogeographic patterns among all five closely related species within subgenus Nothofagus including $N$. pumilio support the hypothesis that cpDNA polymorphisms reflect an ancient evolutionary history that was maintained by cycles of hybridization and introgression (Acosta \& Premoli 2010). Nonetheless, long-lasting persistence throughout the ice ages along the entire range of $N$. pumilio in areas as south as Tierra del Fuego has preserved ancient phylogeographic patterns. In particular, north and south lineages diverged as a product of vicariance due to a marine ingression during the Mid Tertiary which was later colonized 


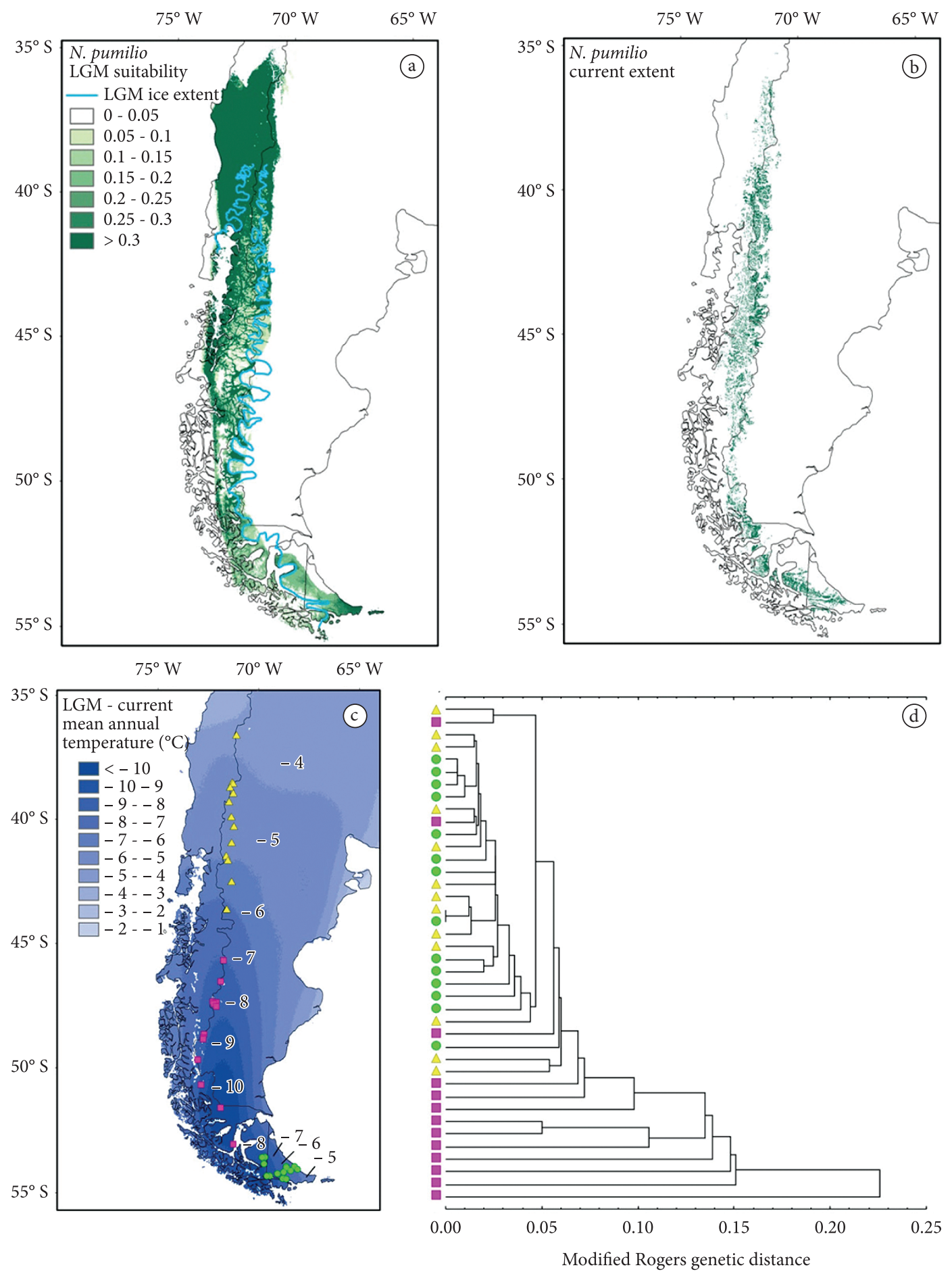

Figure 4. a) Modeled distribution of Nothofagus pumilio during Last Glacial Maximum in southern South America using the Maxent model based on the NCAR-CCSM GCM; b) Modeled present-day distribution of Nothofagus pumilio forests; c) LGM-modern difference in mean annual temperature simulated by the NCAR-CCSM GCM. Superimposed are site locations of populations sampled for genetic analyses (Tierra del Fuego Island green circles, mid-latitude magenta squares, and northerly populations yellow triangles), and d) Multivariate cluster analysis based on isozyme data of Nothofagus pumilio populations along its entire range; coding corresponds to that described in panel c.

from austral latitudes as depicted by the haplotype derived from southern ancestors (Premoli et al. 2012). Hence, the evidence presented here strongly suggests that mid latitude N. pumilio can be considered an area of secondary contact.
Our ENM hindcasts of both N. pumilio and P. parlatorei are only one of multiple models of possible paleodistributions of these forests based on a single atmosphere-ocean general circulation models and performed using one of 
multiple possible niche modeling methods and, thus, carry considerable degrees of uncertainty (Collevatti et al. 2012). In the case of the southern forests, this problem is relatively alleviated compared to more species-rich biomes by the fact that these are monospecific forests. Given these limitations, as proposed by others (e.g. Waltari et al. 2007; Collevatti et al. 2012) we use these models only in direct association with molecular phylogeographic and if available with paleoecological evidence.

A growing body of evidence suggests that cold-tolerant (i.e. microthermic) tree species were able to survive in refugia within colder areas within temperate regions (Bhagwat \& Willis 2008; Tollefsrud et al. 2008). During coolig, cold-hardy species from temperate regions probably survived in multiple locations (multiple refugia hypothesis, Premoli et al. 2000) along their current distribution and/or even expanded their ranges as in mountain subtropical habitats. As a result of such long-term persistence, cold-tolerant trees as Nothofagus and Podocarpus have preserved genetic variants which may guide conservation and management actions. In temperate areas ancient lineages as $N$. pumilio responded vigorously to climatic oscillations of the Quaternary and persisted locally thus preserving ancient genetic patterns (Premoli et al. 2010). Major genetic differentiation by cpDNA of N. pumilio occurred mainly due to Tertiary forces significantly controlled by geology (Mathiasen \& Premoli 2010). In tropical areas, unique haplotypes and distinctive isozyme variants towards the southern range of $P$. parlatorei highlights the relevance of these populations as a reservoir of genetic diversity (Quiroga \& Premoli 2007). While P. parlatorei is internationally protected under CITES Appendix I, and large populations are located within conservation units of Argentina and Bolivia, the most genetically variable populations of the southern sector are outside protected areas. The data presented here shows that montane tropical forests have probably faced local range contractions during past warm periods. However, increasing fragmentation under current warming trends may impose new conditions. Nonetheless, alike among-population divergence yielded by nuclear and relatively conserved DNA sequences of the chloroplast suggests that $P$. parlatorei populations have maintained continuous gene throughout its range (Quiroga et al. 2012). In order to preserve historical and contemporaneous gene flow rates, population connectivity should be considered into the design of conservation actions.

\section{Acknowledgements}

We thank the editor JAF Diniz Filho and an anonymous reviewer for their insightful comments and S. Pacheco from Fundación Proyungas for assisting with Figure 2. Authors are members of CONICET.

\section{References}

Acosta MC \& Premoli AC, 2010. Evidence of chloroplast capture in South American Nothofagus (subgenus Nothofagus, Nothofagaceae). Molecular Phylogenetics and
Evolution, 54:235-242. PMid:19683588. http://dx.doi. org/10.1016/j.ympev.2009.08.008

Bandelt HJ, Forster P \& Röhl A, 1999. Median-joining networks for inferring intraspecific phylogenies. Molecular Biology and Evolution, 16:37-48. Available from: http://www. fluxus-technology.com/sharenet.htm. PMid:10331250. http://dx.doi.org/10.1093/oxfordjournals.molbev.a026036

Bhagwat SA \& Willis KJ, 2008. Species persistence in northerly glacial refugia of Europe: a matter of chance or biogeographical traits? Journal of Biogeography, 35:464-482. http://dx.doi.org/10.1111/j.1365-2699.2007.01861.x

Bush MB, 2002. Distributional change and conservation on the Andean flank: a palaeoecological perspective. Global Ecology and Biogeography, 11:463-473. http://dx.doi. org/10.1046/j.1466-822X.2002.00305.x

Carnaval AC \& Moritz C, 2008. Historical change modeling predicts patterns of current biodiversity in the Brazilian Atlantic forest. Journal of Biogeography, 35:1187-1201. http:// dx.doi.org/10.1111/j.1365-2699.2007.01870.x

Clauzet G, Wainer I \& Bicego M, 2008. Validating NCAR-CCSM last glacial maximum sea surface temperature in the tropical and south atlantic with proxy-data. Palaeogeography, Palaeoclimatology, Palaeoecology, 267:153-160. http:// dx.doi.org/10.1016/j.palaeo.2008.06.004

Collevatti RG et al., 2012. A coupled phylogeographical and species distribution modelling approach recovers the demographical history of a Neotropical seasonally dry forest tree species. Molecular Ecology, 21: 5845-5863. PMid:23094833. http://dx.doi.org/10.1111/mec.12071

Collins WD et al., 2004. The community climate system model: CCSM3. Journal of Climate, 19:2122-2143. http://dx.doi. org/10.1175/JCLI3761.1

Colinvaux PA \& De Oliveira PE, 2001. Amazon plant diversity and climate through the Cenozoic. Palaeogeography, Palaeoclimatology, Palaeoecology, 166:51-63. http://dx.doi. org/10.1016/S0031-0182(00)00201-7

Hewitt GM, 2000. The genetic legacy of the Quaternary ice ages. Nature, 405:907-913. PMid:10879524. http://dx.doi. org/10.1038/35016000

Hill RS, 2001. Biogeography, evolution and palaeoecology of Nothofagus (Nothofagaceae): the contribution of the fossil record. Australian Journal of Botany, 49:321-332. http:// dx.doi.org/10.1071/BT00026

Hijmans RJ et al., 2005. Very high resolution interpolated climate surfaces for global land areas. International Journal of Climatology, 25:1965-1978. http://dx.doi.org/10.1002/ joc. 1276

Hooghiemstra H, Wijninga VM \& Cleef AM, 2006. The paleobotanical record of Colombia: implications for biogeography and biodiversity. Annals of the Missouri Botanical Garden, 93:297-324. http://dx.doi. org/10.3417/0026-6493(2006)93[297:TPROCI]2.0.CO;2

Hulton NRJ et al., 2002. The Last Glacial Maximum and deglaciation in southern South America. Quaternary Science Reviews, 21:233-241. http://dx.doi.org/10.1016/ S0277-3791(01)00103-2 
Kershaw AP \& McGlone M, 1995. The Quaternary history of the southern conifers. In: Enright N \& Hill RS (eds.). The Ecology of the Southern Conifers. Melbourne: Melbourne University Press. p. 30-63.

Knapp M et al., 2005. Relaxed molecular clock provides evidence for long-distance dispersal of Nothofagus (Southern Beech). PLoS Biology, 3(1):e14. http://dx.doi.org/10.1371/journal. pbio.0030014

Knowles LL \& Alvarado-Serrano DF, 2010. Exploring the population genetic consequences of the colonization process with spatio-temporally explicit models: insights from coupled ecological, demographic and genetic models in montane grasshoppers. Molecular Ecology, 19:3727-3745. PMid:20723059. http://dx.doi. org/10.1111/j.1365-294X.2010.04702.X

Knowles LL, Carstens BC \& Keat ML, 2007. Coupling genetic and ecological-niche models to examine how past population distributions contribute to divergence. Current Biology, 17:1-7. PMid:17475496. http://dx.doi.org/10.1016/j. cub.2007.04.033

Markgraf V, McGlone M \& Hope G, 1995. Neogene paleoenvironmental and paleoclimatic change in southern temperate ecosystems - a southern perspective. Trends in Ecology and Evolution, 10:143-147. http://dx.doi.org/10.1016/ S0169-5347(00)89023-0

Martínez-Meyer E \& Peterson AT, 2006. Conservatism of ecological niche characteristics in North American plant species over the Pleistocene-to-Recent transition. Journal of Biogeography, 33:1779-1789. http://dx.doi. org/10.1111/j.1365-2699.2006.01482_33_10.x

Mathiasen P \& Premoli AC, 2010. Out in the cold: genetic variation of Nothofagus pumilio (Nothofagaceae) provides evidence for latitudinally distinct evolutionary histories in austral South America. Molecular Ecology, 19:371-385. PMid:20002584. http://dx.doi. org/10.1111/j.1365-294X.2009.04456.X

Petit RJ et al., 2003. Glacial refugia: hotspots but not melting pots of genetic diversity. Science, 300:1563-1565. PMid:12791991. http://dx.doi.org/10.1126/science.1083264

Phillips SJ et al., 2006. Maximum entropy modeling of species geographic distributions. Ecological Modeling, 190:231-259 http://dx.doi.org/10.1016/j.ecolmodel.2005.03.026

Premoli A, Kitzberger T \& Veblen T, 2000. Isozyme variation and recent biogeographical history of the long-lived conifer Fitzroya cupressoides. Journal of Biogeography, 27:251-260. http://dx.doi.org/10.1046/j.1365-2699.2000.00402.x

Premoli AC et al., 2012. Phylogeographically concordant chloroplast DNA divergence in sympatric Nothofagus s.s. How deep can it be? New Phytologist, 193:261-275. PMid:21883239. http://dx.doi.org/10.1111/j.1469-8137.2011.03861.x

Premoli AC, Mathiasen P \& Kitzberger T, 2010. Southernmost Nothofagus trees enduring ice ages: genetic evidence and ecological niche retrodiction reveal high latitude $\left(54^{\circ} \mathrm{S}\right)$ glacial refugia. Palaeogeography, Palaeoclimatology, Palaeoecology, 298:247-256. http://dx.doi.org/10.1016/j. palaeo.2010.09.030

Quiroga MP \& Premoli A, 2007. Genetic patterns in Podocarpus parlatorei reveal the long-term persistence of cold-tolerant elements in the southern Yungas. Journal of Biogeography, 34:447-455. http://dx.doi. org/10.1111/j.1365-2699.2006.01613.x

Quiroga et al., 2012. Shrinking Forests under Warming: Evidence of Podocarpus parlatorei (pino del cerro) from the Subtropical Andes. Journal of Heredity, 103:682-691. PMid:22563123. http://dx.doi.org/10.1093/jhered/ess031

Rull V, 2009. Microrefugia. Journal of Biogeography, 36:481-484. http://dx.doi.org/10.1111/j.1365-2699.2008.02023.x

Sersic et al., 2011. Emerging phylogeographical patterns of plants and terrestrial vertebrates from Patagonia. Biological Journal of the Linnean Society, 103:475-494. http://dx.doi. org/10.1111/j.1095-8312.2011.01656.x

Tamura Ket al., 2007. MEGA4: Molecular Evolutionary Genetics Analysis (MEGA) software version 4.0. Molecular Biology and Evolution, 24: 1596-1599. Available from: http://www. megasoftware.net/mega.html. PMid:17488738. http://dx.doi. org $/ 10.1093 / \mathrm{molbev} / \mathrm{msm} 092$

Tollefsrud MM et al., 2008. Genetic consequences of glacial survival and postglacial colonization in Norway spruce: combined analysis of mitochondrial DNA and fossil pollen. Molecular Ecology, 17:4134-4150. PMid:19238710. http:// dx.doi.org/10.1111/j.1365-294X.2008.03893.x

Van Steenis CGGJ, 1971. Nothofagus, key genus of plant geography, in time and space, living and fossil, ecology and phylogeny. Blumea, 19:65-98.

Villagrán C, 1991. Desarrollo de tundras Magallánicas durante la transición glacial-postglacial en la Cordillera de la Costa de Chile, Chiloé: ¿Evidencias de un evento equivalente al "Jounger Dryas". Bamberger Geographische Schriften, 11:1-12.

Villagrán C \& Hinojosa LF, 2005. Esquema Biogeográfico de Chile. In: Bousquets JL, Morrone JJ (eds.). Regionalización biogeográfica en Iberoamérica y tópicos afines. México: Ediciones de la Universidad Nacional Autónoma de México, Jiménez Editores. p. 551-577.

Waltari E et al., 2007. Locating Pleistocene refugia: comparing phylogeographic and ecological niche model predictions. PLoS One, 2(7):e563. PMid:17622339 PMCid:1905943. http://dx.doi.org/10.1371/journal.pone.0000563 